\title{
Recent Synthetic Approaches to Inner-core Oligosaccharides of Lipopolysaccharides and Lipooligosaccharides
}

\author{
Tsuyoshi Ichiyanagi \\ Faculty of Agriculture, Tottori University, 4-101 Koyama-cho minami, Tottori 680-8553, Japan \\ FAX: +81-857-31-6732, E-mail: yanagi@muses.tottori-u.ac.jp \\ (Received on November 14, 2017, accepted on December 7, 2017)
}

Key Words: lipopolysaccharide, lipooligosaccharide, inner core, 3-deoxy-D-manno-oct-2-ulosonic acid

\begin{abstract}
Lipopolysaccharides (LPSs) and lipooligosaccharides (LOSs) are target molecules for the development of vaccines against pathogenic Gram-negative bacterial infections. The chemical synthesis of the core oligosaccharides of LPSs/LOSs remains a major challenge. Herein, recent reports of the chemical synthesis of inner-core oligosaccharides containing 3-deoxy-D-manno-oct-2-ulosonic acid are reviewed.
\end{abstract}

\section{A. Introduction}

Lipopolysaccharides (LPSs) and lipooligosaccharides (LOSs) are glycolipids found in the outer membranes of Gram-negative bacteria. They are not only essential for maintaining their life but well known for their immunological, pharmacological and pathophysiological effects displayed in eukaryotic cells and organisms (Fig. 1). Alongside capsular polysaccharides, pili, and extracellular proteins, LPSs and LOSs are important targets in the biological defense response against bacterial infection and their study is vital for elucidating the mechanism of this response and developing vaccines.

LPSs are composed of three components, namely, lipid A, a core oligosaccharide, and an $\mathrm{O}$-antigen polysaccharide, whereas LOSs lack the $\mathrm{O}$ antigen. The core oligosaccharide can be divided into inner core and outer core regions, where the inner core is made up of the high-carbon sugars 3-deoxy-D-manno-oct-2-ulosonic acid (Kdo) and L-glycero-D-mannoheptose (Hep). As these sugars are not found in mammals, they have received attention for their potential use as antigens in vaccines against pathogenic Gram-negative bacteria.

\section{Fig. 1. Biological activity of LPS.}

a) organism level

pyrogenicity, leucopenia, thrombocytopenia, hypoglycemia, hypoferremia, hypotensive action, intravascular coagulation, immunologic enhancement

b) cell level

macrophage activation, macrophage migration inhibition, lymphocyte mitogenic activation, prostaglandin production, anti-tumor activity, microglia activation

c) molecular level complement activation, cytokine production, plasminogen activation
The structures of the inner-core oligosaccharides of LPSs and LOSs have rich diversity but tend to be highly conserved within a genus. The biological function of the inner core has not yet been clarified. Investigations into the chemical synthesis of inner-core oligosaccharides began in the mid-1980s, although their construction remains challenging. This is because the two main components, Kdo and Hep, are not readily available for the synthesis, and the stereoselectivity of glycosylation using Kdo donors cannot be easily controlled.

Biosynthesis of glycans of LPS is also complicated as well as other glycans due to primarily determined by the glycosyltransferases that assemble monosaccharide moieties into linear and branched glycan chain. Therefore it is difficult to obtain the innercore oligosaccharides of LPSs and LOSs in a pure form through a molecular biological approach. To circumvent this problem, chemical methods have been applied to achieve the synthesis of innercore oligosaccharides. This mini review summarizes the latest advances in the chemical synthesis of Kdo-containing inner-core oligosaccharides of LPSs and LOSs.

\section{B. Synthesis of Kdo-containing LPS Inner-core Oligo- saccharide}

Zamyatina et al. reported the synthesis of a disaccharide containing 4-amino-4-deoxy-L-arabinose (Ara4N), which is part of the inner-core oligosaccharide of the LPS produced by Burkholderia sp. (1). (Scheme 1). Glycosylation of the $N$-phenyltrifluoroacetimidate 1 derived from 2,3-di-O-benzyl 4-azido-4-deoxy-L-arabinose with the D-glycero-D-taro-oct-2-ulosonicacid (Ko) derivative 2 afforded the 1,8-and 1,7-linked disaccharides ( $3 \boldsymbol{\alpha}, \boldsymbol{\beta}$ and 4$)$ in $84 \%$ yield with moderate regio- and poor stereoselectivity. The separation of these products was easily achieved after removal of the $\alpha$ 1-8 linked disaccharide and subsequent deacetylation of the $\beta-1,8$ 

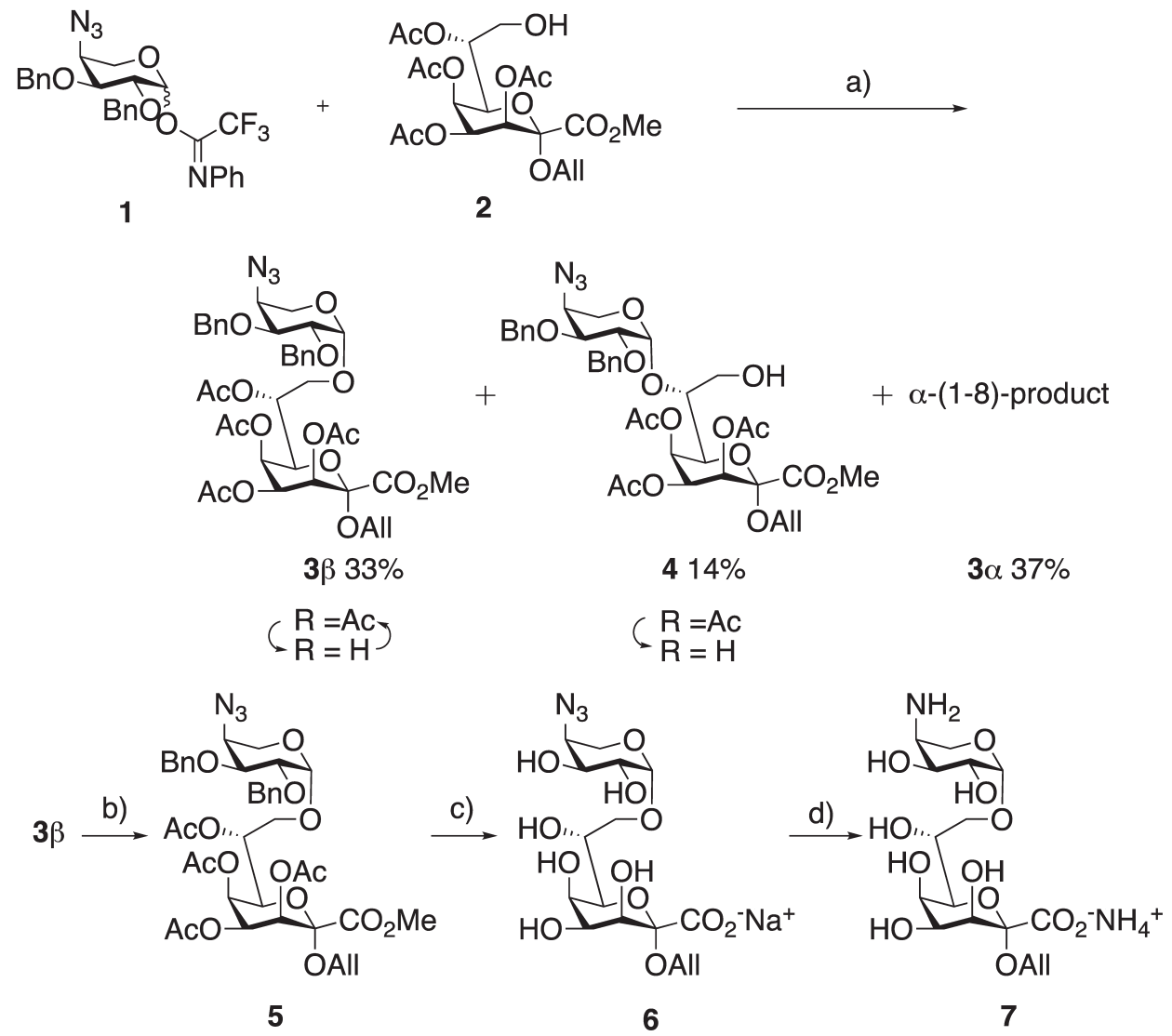

Scheme 1. Synthesis of Ara4N-(1-8)-Ko disaccharide. Reagents and conditions: a) $\left.\mathrm{TMSOTf}^{-}-25^{\circ} \mathrm{C}, \mathrm{b}\right)$ i) $\mathrm{TiCl}_{4}, 0^{\circ} \mathrm{C}$, ii) $\mathrm{Ac}_{2} \mathrm{O} 89 \%$, c) i) $\mathrm{NaOMe}$, ii) $\mathrm{NaOH}, 97 \%$. d) DTT, $\mathrm{NH}_{3}, 60 \%$.

and $\beta$-1,7 derivatives under Zemplén conditions. In another study, glycosylation of the 8-OH position of the Kdo derivative 8 afforded the core disaccharide $\mathbf{1 2}$ of the LPSs from Proteus mirabilis and Proteus penneri (Scheme 2). In addition, glycosylation of triol 9 with Kdo bromide 13 under Helferich conditions gave a branched core trisaccharide $\beta$-Ara4N-(1-8)- $\alpha$-Ko-(2-4)-Kdo 17 of the LPS from Proteus mirabilis.

Pokorny et al. reported the synthesis of the inner-core trisaccharide and branched tetrasaccharide of the Chlamydia LPS using the 3-iodo-Kdo fluoride $\mathbf{1 8}$ as the glycosyl donor (2) (Scheme 3). One-pot glycosylation of the Kdo donor $\mathbf{1 8}$ and tetraol acceptor 19 afforded the desired Kdo trisaccharide 20, $\alpha$-Kdo-(2-4) $[\alpha-\mathrm{Kdo}-(2-$ $8)]-K d o$, as the major product in $58 \%$ yield, alongside its regioisomer, $\alpha$-Kdo-(2-4)[ $\alpha$-Kdo-(2-7)]-Kdo, in 7\% yield. This result seems to indicate that the reactivity of the hydroxyl groups of Kdo derivatives is in the order of $4-\mathrm{OH} \gg 8-\mathrm{OH}>7-\mathrm{OH}>5-\mathrm{OH}$. In these glycosylation reactions, a Kdo donor is less reactive than other neutral aldose-type donors because of steric and electronic factors arising from the $\mathrm{C} 1$ carboxyl group in the Kdo donor. In addition, control of the stereoselectivity under glycosylation conditions is very difficult due to the lack of a neighboring functional group at the $\mathrm{C} 3$ position; however, the use of 3-iodo-Kdo fluoride as the donor solves these problems. By applying this method, the first synthesis of an $\alpha-2,5$ linked Kdo dimer 24 containing the inner core of the Acinetobacter LPS was achieved (3) (Scheme 4).

Yang et al. reported the synthesis of the inner-core tetrasaccharides of LPSs from Yersinia pestis, Haemophilus influenzae, and Proteus sp. using the disaccharide $\alpha$-L,D-Hep-(1-3)- $\alpha$-L,DHep-(1-5)-Kdo derivative $\mathbf{2 5}$ as a common building block $(4,5)$ (Scheme 5). The key features of this synthesis are (a) preparation of Hep units with various protecting groups by de novo synthesis from Hep derivatives, and (b) glycosylation of the Kdo derivative $\mathbf{2 5}$ at the 4-position with the oligosaccharide donors 26-28 prepared from these protected Hep units to afford a variety of oligosaccharide structures 29-31. In this synthesis of 25, the acetyl protecting group at the 2-position of the reducing Hep unit of the donor was considered to have a neighboring-group effect (6).

Huang et al. designed a 5,7-O-di-tert-butylsilylene (DTBS)protected Kdo ethyl thioglycoside as a Kdo donor. Glycosylation using this donor with primary and secondary glycosyl acceptors 


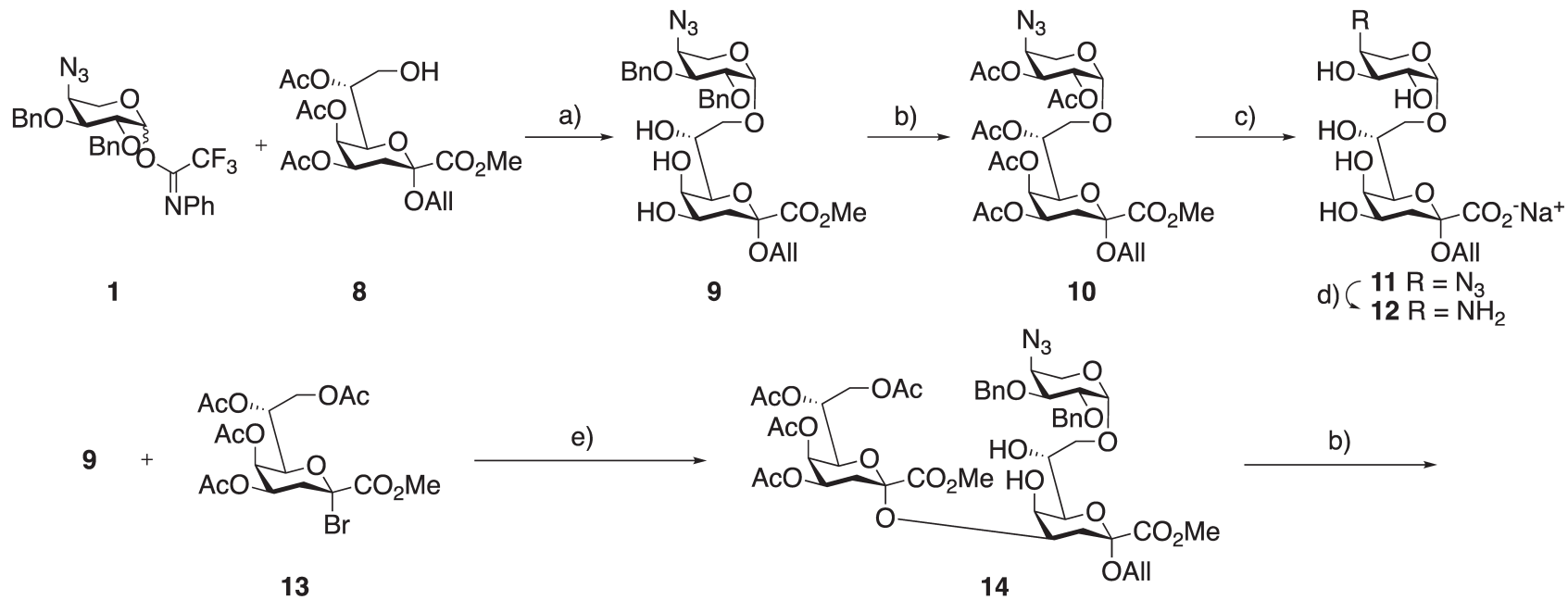

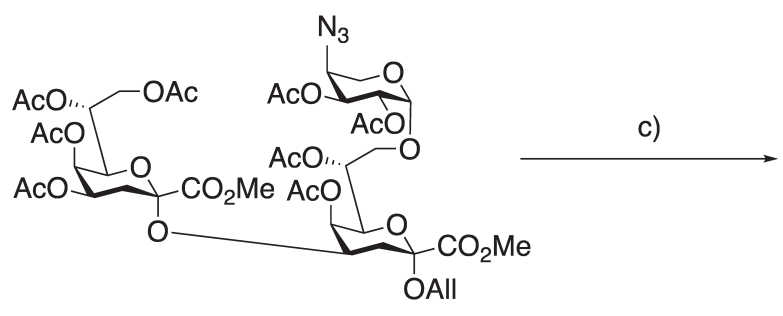

15

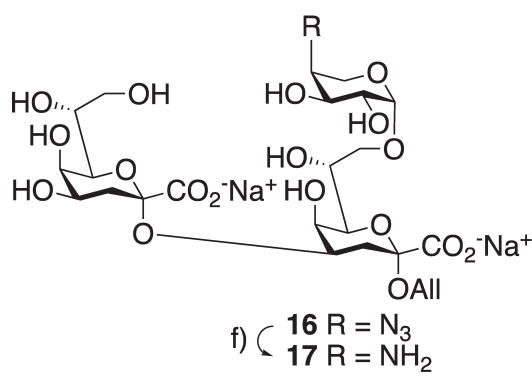

Scheme 2. Synthesis of $\boldsymbol{P}$. mirabilis and $\boldsymbol{P}$. Penneri di- and trisaccharide. Reagents and conditions: a) $\mathbf{3 3}$, TMSOTf, $\left.-25^{\circ} \mathrm{C}, \mathrm{b}\right) \mathrm{Ac}_{2} \mathrm{O}$, ii) $\mathrm{TiCl}_{4}, 0$ ${ }^{\circ} \mathrm{C}$, iii) $\mathrm{Ac}_{2} \mathrm{O}$, $\left(68 \%\right.$, 11) $\left(51 \%\right.$, 16). c) i) $\mathrm{NaOMe}$, ii) $\mathrm{NaOH}\left(98 \%\right.$, 12), (96\%, 17). d) DTT, $\mathrm{NH}_{3} 60 \%$. e) $\mathrm{Hg}(\mathrm{OAc})_{2}, \mathrm{CH}_{3} \mathrm{NO}_{2}, 19 \%$. f) $\mathrm{Me}_{3} \mathrm{P}$, $\mathrm{THF}, 99 \%$.

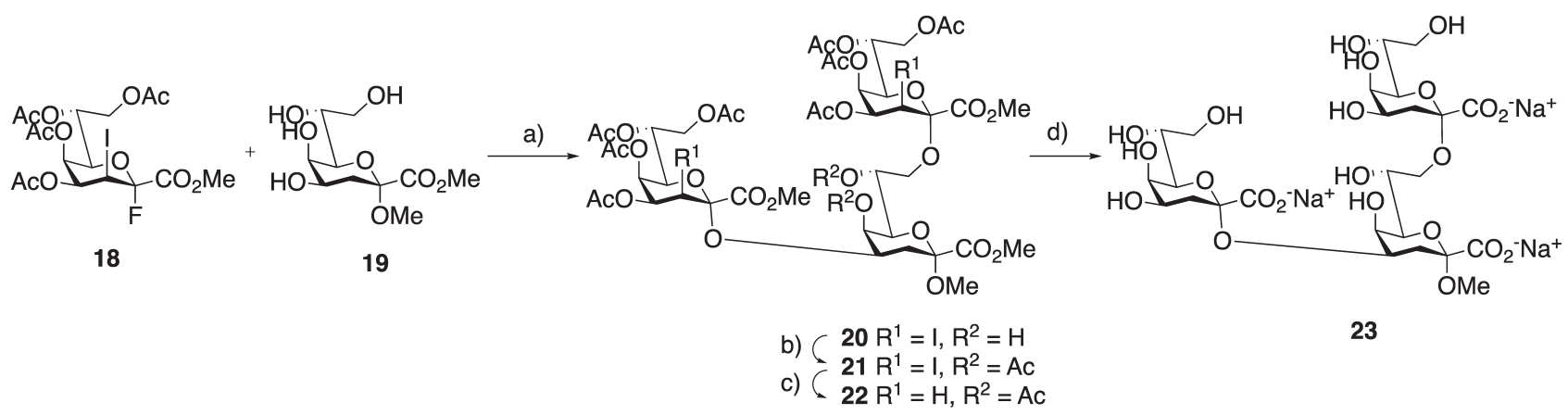

Scheme 3. Synthesis of the family-specific Chlamydia Kdo trisaccharide. Reagents and conditions: a) $\mathrm{BF}_{3} \cdot \mathrm{OEt}_{2}, \mathrm{CH}_{2} \mathrm{Cl}_{2}, \mathrm{MS}_{3 \mathrm{~A}} 58 \%$. b) $\mathrm{Ac}_{2} \mathrm{O}$, Pyridine, DMAP, 95\%. c) lauroyl peroxide, cyclohexane $88 \%$. d) $0.1 \mathrm{M} \mathrm{NaOMe}, \mathrm{MeOH}$, then $0.1 \mathrm{M}$ aq. $\mathrm{NaOH} 71 \%$.

gave the corresponding $\alpha$-glycosides in moderate to excellent yields with complete selectivity (7). To demonstrate the utility of this approach, they applied it to the synthesis of the 4,8-branched trisaccharide present in the core structure of Burkholderia and Proteus LPSs. Glycosylation of allyl alcohol with thioglycoside 32 afforded $\alpha$-allyl glycoside $\mathbf{3 3}$ as the sole product (Scheme 6). Subsequently, glycosylation with Ara4N donor 1 gave the corresponding 1,8-linked disaccharides $35 \boldsymbol{\alpha}, \boldsymbol{\beta}$ in excellent yield with low stereoselectivity $(1: 1.5)$. After separation of these diastereomers, the disaccharide $\mathbf{3 5} \alpha$ was coupled with the Kdo donor 32 to deliver the 4,8-branched trisaccharide 37 in good yield. In addition, the synthesis of a common LPS epitope of the human pathogen Chlamydia, $\alpha$-Kdo-(2-8)- $\alpha$-Kdo-(2-4)- $\alpha$-Kdo trisaccharide, was also demonstrated.

Boltje et al. reported that the disaccharide $\mathbf{3 8}$ modified by the orthogonal protecting groups diethylisopropylsilyl (DEIPS), 2-naphthyl (Nap), allyl (All), and levulinoyl (Lev) can serve as a reliable key compound for the synthesis of the inner core of LPSs (8) (Scheme 7). The ability to selectively remove the various protecting groups in the desired order allowed the optimal coupling 


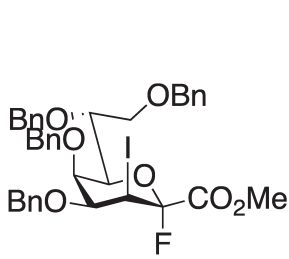

18

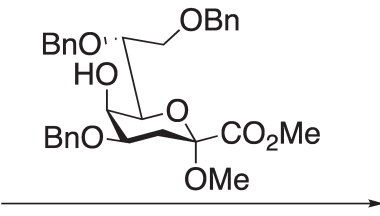

a)

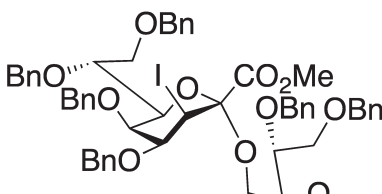<smiles>COCC(C)(OC)OCC1CCCCC1OC</smiles>

b)

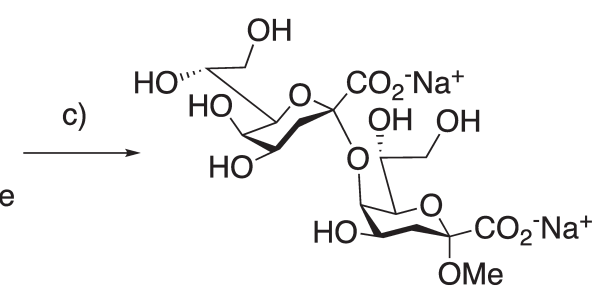

24

Scheme 4. Glycosylation and deprotection towards the $\boldsymbol{\alpha}-(2-5) \mathbf{K d o}$ disaccharide. Reagents and conditions:a) $\mathrm{BF}_{3} \cdot \mathrm{OEt}_{2}$, toluene, $^{-4}-40^{\circ} \mathrm{C}$ to $-15^{\circ} \mathrm{C}, 2 \mathrm{~h},-15^{\circ} \mathrm{C}$ to $-10^{\circ} \mathrm{C}, 1.5 \mathrm{~h}, 71 \%$. b) i) $\mathrm{Pd}(\mathrm{OH})_{2} / \mathrm{C}, \mathrm{H}_{2}, \mathrm{MeOH}, \mathrm{NaOAc}, \mathrm{rt}, 1 \mathrm{~h}$, ii) $\mathrm{Pd} / \mathrm{C}, \mathrm{H}_{2}, \mathrm{MeOH}, \mathrm{rt}, 20 \mathrm{~h}$, iii) $\mathrm{Ac} \mathrm{O}_{2} \mathrm{O}, \mathrm{DMAP}, \mathrm{pyr}, \mathrm{rt}, 24 \mathrm{~h}$, $61 \%$; c) i) $\mathrm{NaOMe} \mathrm{MeOH}, \mathrm{rt}, 16 \mathrm{~h}$, ii) $\mathrm{NaOH}, \mathrm{H}_{2} \mathrm{O}, 0^{\circ} \mathrm{C}, 2 \mathrm{~h}$ then rt $4 \mathrm{~h}, 90 \%$.
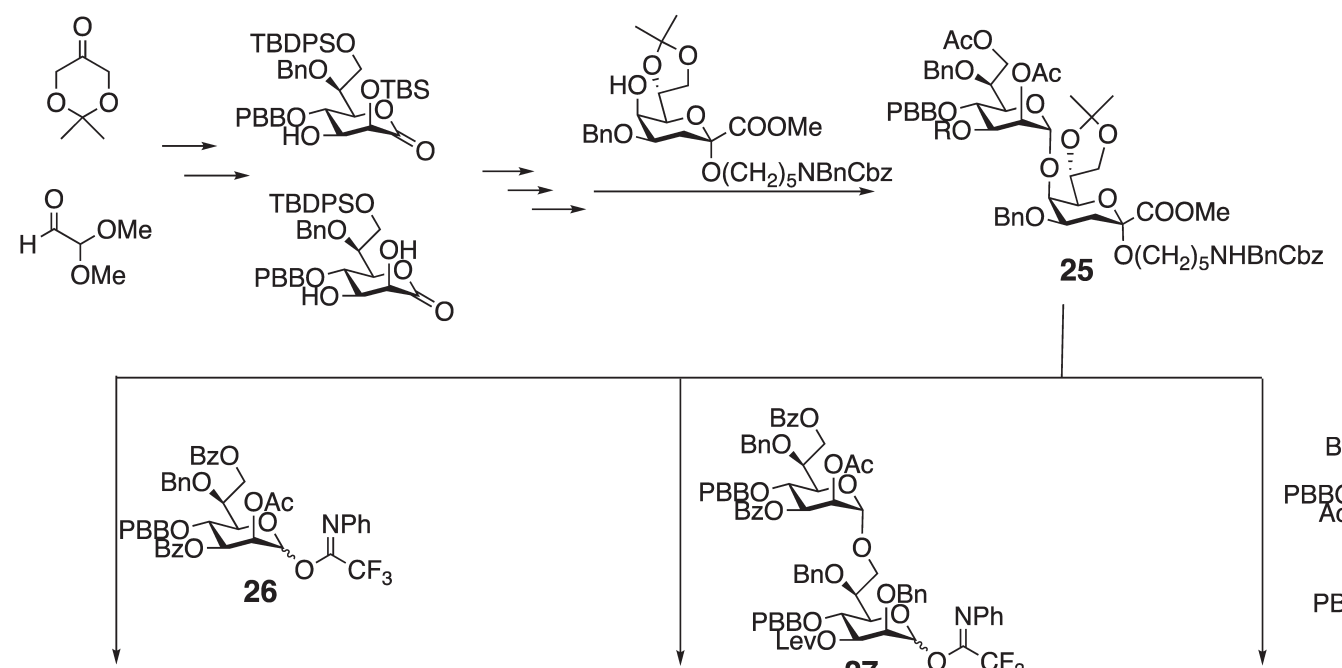

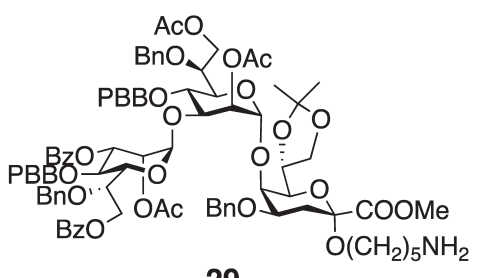

29<smiles>C=[V]C</smiles>

$\alpha-\mathrm{L}, \mathrm{D}-\mathrm{Hep} p-(1-3)-\alpha-\mathrm{L}, \mathrm{D}-\mathrm{Hep} p-(1-5)$ $-\alpha$-D-Kdop-linker

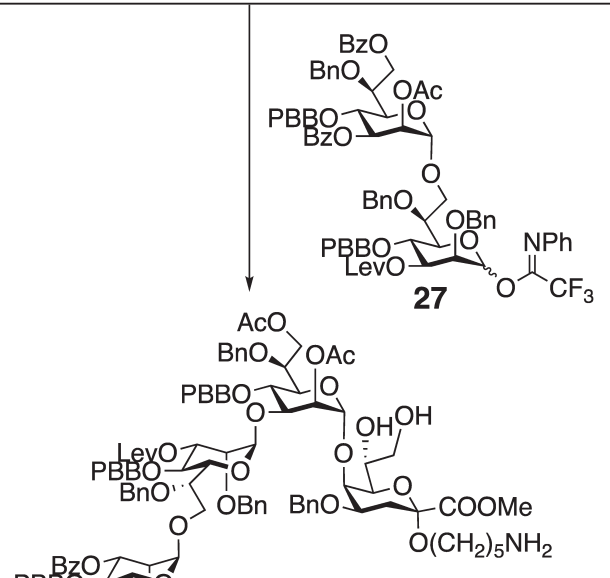

30<smiles>C=[V]C</smiles>

$\alpha-\mathrm{L}, \mathrm{D}-\mathrm{Hep} p-(1-7)-\alpha-\mathrm{L}, \mathrm{D}-\mathrm{Hep} p-(1-3)-$ $\alpha$-L,D-Hep $p-(1-5)-\alpha-\mathrm{D}-\mathrm{Kdo} p$-linker

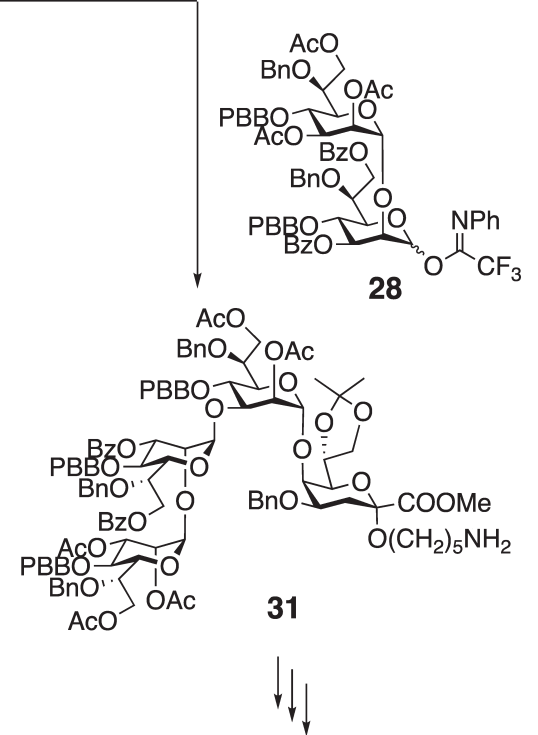

$\alpha-\mathrm{L}, \mathrm{D}-\mathrm{Hep} p-(1-2)-\alpha-\mathrm{L}, \mathrm{D}-\mathrm{Hep} p-(1-3)-$ $\alpha$-L,D-Hepp-(1-5)- $\alpha$-D-Kdop-linker

Scheme 5. Synthesis of the inner-core oligosaccharides 26-28. Reagents and conditions: TMSOTf, $4 \mathrm{~A} \mathrm{MS}, \mathrm{CH}_{2} \mathrm{Cl}_{2}, \mathrm{Et}_{2} \mathrm{O}, 0^{\circ} \mathrm{C}$, to rt, $73 \%, 26$, $67 \%, 27,65 \%, 28$ ). 


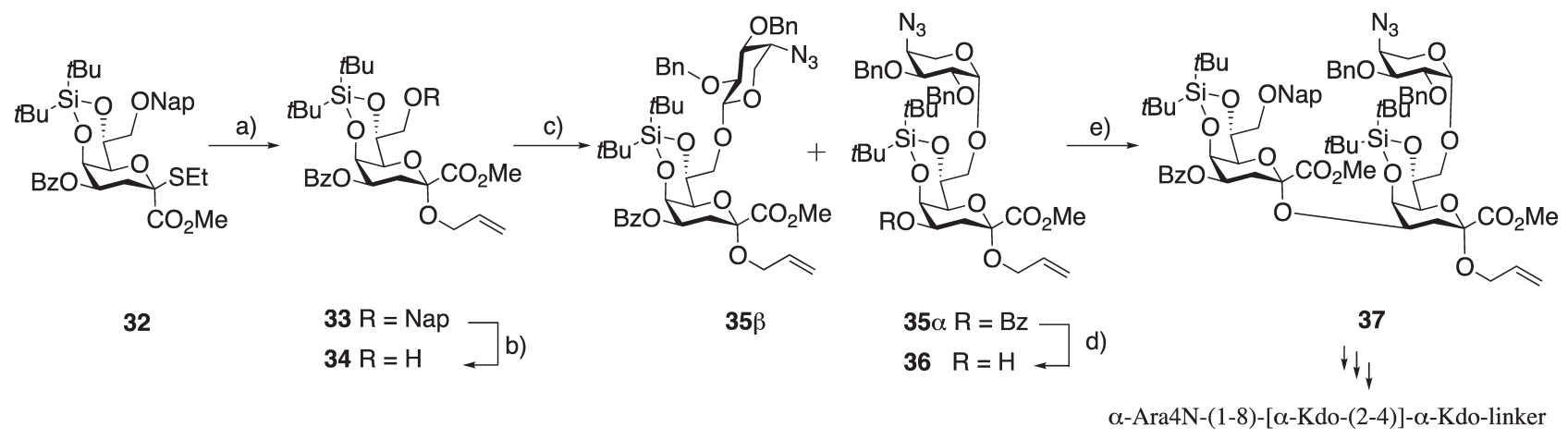

Scheme 6. Synthesis of $\boldsymbol{\alpha}$-Kdo-(2-4)-[ $\boldsymbol{\beta}$-Ara4N-(1-8)]-Kdo trisaccharide. Reagents and conditions: a) allyl alcohol, $\mathrm{TBPA}, \mathrm{CH}_{3} \mathrm{CN}, \mathrm{ice}$ bath, $2 \mathrm{~h}, 87 \%$, $\alpha$ only; b) DDQ, $\mathrm{CH}_{2} \mathrm{Cl}_{2}-\mathrm{MeOH}(5: 1)$, rt, $85 \%$; c) 1, TMSOTf, $\mathrm{CH}_{2} \mathrm{Cl}_{2}-\mathrm{Et}_{2} \mathrm{O}(1: 1),-78^{\circ} \mathrm{C}$ to rt, $\left.90 \%, \alpha / \beta=1: 1.5 ; \mathrm{d}\right) \mathrm{NaOMe}, \mathrm{MeOH}, \mathrm{rt}$, $3 \mathrm{~h}, 92 \%$; e) 32, TBPA, $\mathrm{CH}_{3} \mathrm{CN}, \mathrm{H}_{3} \mathrm{CN}$, ice bath, $2 \mathrm{~h}, 67 \%$, $\alpha$ only.

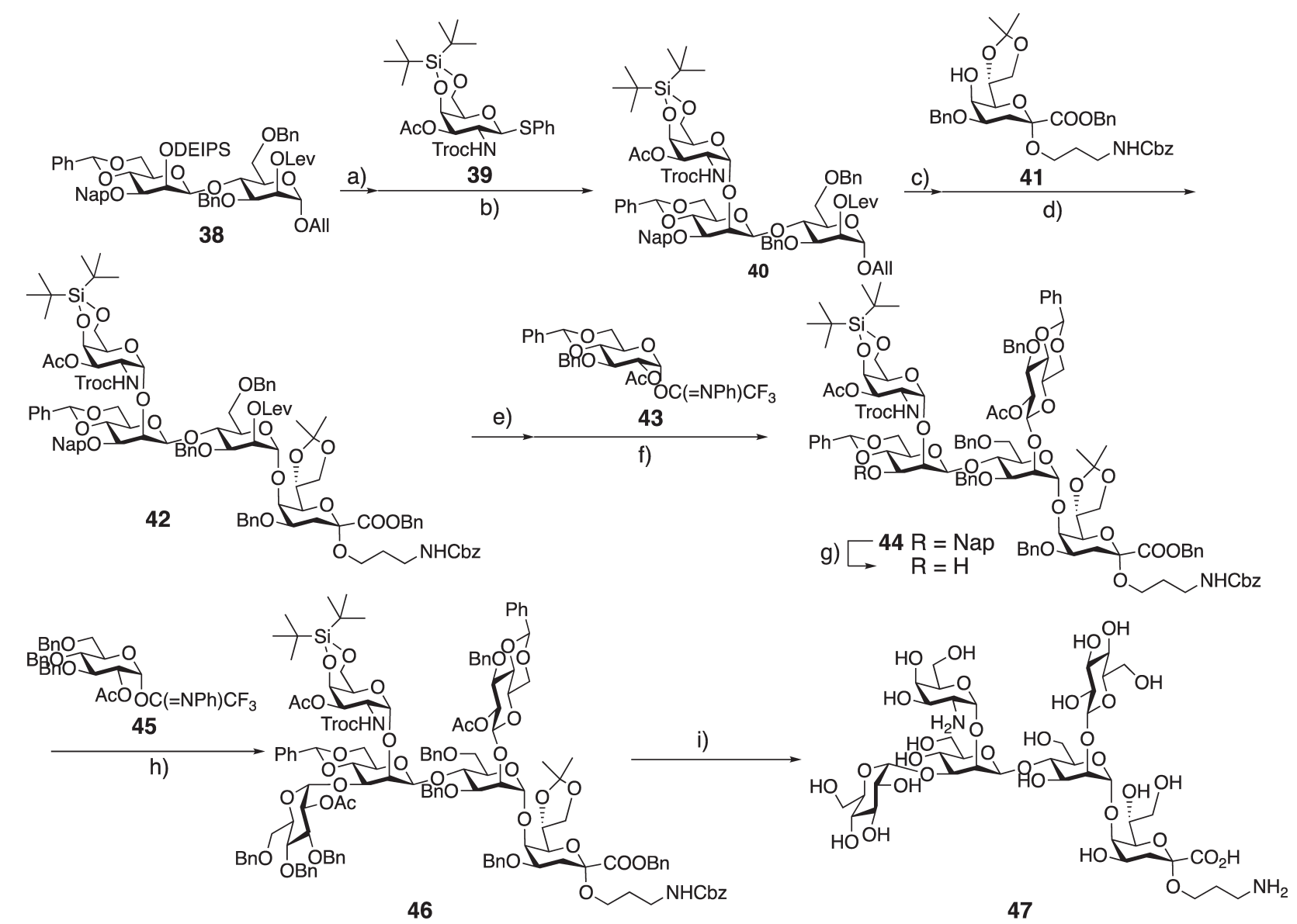

Scheme 7. Synthesis of the inner core of $\boldsymbol{F}$. tularensis. Reagents and conditions: a) TBAF, AcOH, THF, 16h, rt, 98\%. b) NIS, TfOH, $\mathrm{CH}_{2} \mathrm{Cl}_{2}, 10 \mathrm{~min}, 0^{\circ} \mathrm{C}, 77 \%$. c) i) $\mathrm{Pd}\left(\mathrm{PPh}_{3}\right)_{4}, \mathrm{AcOH}, \mathrm{CH}_{2} \mathrm{Cl}_{2}, 3 \mathrm{~h}$, rt then ii) TCA, DBU, $\mathrm{CH}_{2} \mathrm{Cl}_{2}, 1 \mathrm{~h}, \mathrm{rt}, 75 \%$. d) $\mathrm{TfOH}, \mathrm{CH}_{2} \mathrm{Cl}_{2}, 10 \mathrm{~min}, 0^{\circ} \mathrm{C}, 61 \%$. e) $\mathrm{N}_{2} \mathrm{H}_{4} \cdot \mathrm{AcOH}$, EtOH, toluene, $30 \mathrm{~min}, \mathrm{rt}, 78 \%$. f) TfOH, $\mathrm{CH}_{2} \mathrm{Cl}_{2}, 10 \mathrm{~min}, 0^{\circ} \mathrm{C}, 82 \%$. g) DDQ, $\mathrm{CH}_{2} \mathrm{Cl}_{2}, \mathrm{H}_{2} \mathrm{O}, 3 \mathrm{~h}, \mathrm{rt}, 76 \%$. h) $\mathrm{TfOH}, \mathrm{Et}_{2} \mathrm{O}, 10 \mathrm{~min}$, $-35^{\circ} \mathrm{C}, 73 \%$. i) i) TFA, $\mathrm{CH}_{2} \mathrm{Cl}_{2}, \mathrm{H}_{2} \mathrm{O}, 1 \mathrm{~h}$, rt then ii) HF pyridine, THF, 30 min, rt, then iii) $\mathrm{Zn}, \mathrm{AcOH}, \mathrm{CH}_{2} \mathrm{Cl}_{2}, 3 \mathrm{~h}, \mathrm{rt}, 89 \%$, then $\mathrm{NaOMe}, \mathrm{MeOH}$, $\mathrm{H}_{2} \mathrm{O}, \mathrm{THF}, 1 \mathrm{~h}$ rt, $55 \%$, then $\mathrm{Pd}(\mathrm{OH})_{2}, \mathrm{H}_{2}, t-\mathrm{BuOH}, \mathrm{H}_{2} \mathrm{O}, 16 \mathrm{~h}, \mathrm{rt}, 85 \%$.

sequence to be established for the construction of a highly crowded 1,2,3-cis configured branching point. Glycosylation of $\mathbf{3 8}$ using the GalN derivative 39 followed by selective cleavage of the DEIPS group gave the corresponding trisaccharide $\mathbf{4 0}$ in good yield with complete $\alpha$ selectivity. After deprotection of $\mathbf{4 0}$ and conversion of the anomeric allyl ether to the trichloroacetimidate, coupling with 


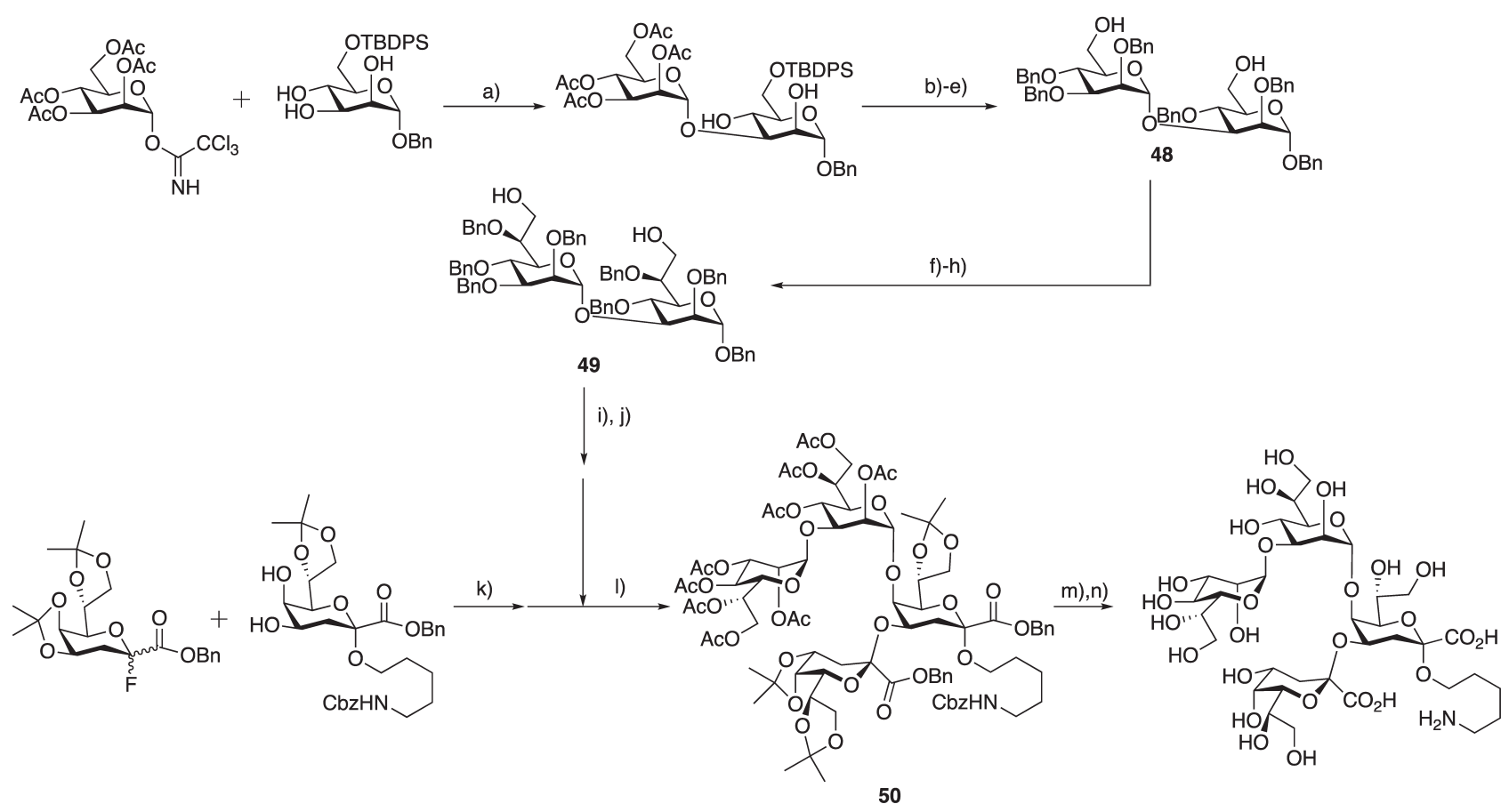

Scheme 8. Synthesis of the inner-core tetrasaccharide of Neisserial LOS. Reagents and conditions: a) TMSOTf, DCM, 45\%. b) NaOMe, $\mathrm{MeOH}$. c) TBDPSCl, pyridine, 79\%. d) $\mathrm{NaH}, \mathrm{BnBr}, \mathrm{DMF}, 57 \%$. e) TBAF, THF, $88 \%$. f) i) $\mathrm{COCl}_{2}, \mathrm{DMSO}_{2} \mathrm{Et}_{3} \mathrm{~N}, \mathrm{DCM}$. ii) vinyl $\mathrm{MgBr}, \mathrm{THF}, 48 \%$ in two steps. g) $\mathrm{NaH}, \mathrm{BnBr}, \mathrm{DMF}, 70 \%$. h) i) $\mathrm{OsO}_{4}, \mathrm{NMO}$, acetone/water, 71\%. ii) $\mathrm{NaIO}_{4}, \mathrm{MeOH} /$ water, $79 \%$. iii) $\mathrm{NaBH}, \mathrm{MeOH} / \mathrm{water}, 91 \%$. i) i) $\mathrm{Pd} / \mathrm{C}, \mathrm{H}_{2}, \mathrm{EtOH}, 93 \%$. ii) $\mathrm{Ac}_{2} \mathrm{O}$, Pyridine, $76 \%$. j) $\mathrm{HBr} / \mathrm{AcOH}, 80 \%$. k) $\mathrm{BF}_{3} \cdot \mathrm{OEt}_{2}, \mathrm{DCM}, 0{ }^{\circ} \mathrm{C}, 25 \%$. 1) AgOTf, DTBMP, DCM. m) TFA $/ \mathrm{H}_{2} \mathrm{O}$ (3:2), DCM. n) i) $\mathrm{Pd} / \mathrm{C}, \mathrm{H}_{2}$, EtOH : water=1:1. ii) $1 \mathrm{M} \mathrm{NaOH}, 34 \%$ over 4 steps.

Kdo unit $\mathbf{4 1}$ gave the linked tetrasaccharide $\mathbf{4 2}$. Coupling with glucose donor $\mathbf{4 3}$ afforded $\beta$-glycoside $\mathbf{4 4}$ after selective deprotection of the levulinoyl group. Finally, oxidative cleavage of the naphthyl group followed by $\beta$-selective glucosylation with glucose donor 45 and full deprotection afforded the inner core of the LPS from Francisella tularensis.

Kong et al. reported the synthesis of the inner-core tetrasaccharide of the Neisseria LOS by the coupling of a Kdo dimer with a Hep dimer (9) (Scheme 8). Disaccharide 49, $\alpha$-Hep-(1-3)-Hep, was prepared from $\alpha$-(1-3)-mannobiose derivative 48 by oxidation of the two hydroxymethyl groups to aldehydes followed by twocarbon elongation using vinylmagnesium bromide and oxidative cleavage of the resulting vinyl group. The diastereoselectivity of the addition reaction was moderate. Coupling reactions with the heptosyl bromide, ethylthio-, trichloroacetimidoyl, and $\mathrm{N}$-phenyltrifluoromethylimidoyl derivatives of $\mathbf{4 9}$ were attempted, but only the use of the glycosyl bromide was successful, affording tetrasaccharide $\mathbf{5 0}$ in $25 \%$ yield $(\alpha: \beta=9: 1)$.

We reported the synthesis of a core oligosaccharide containing a 4,5-branched Kdo structure via fragment condensation. This approach involves the coupling at the 5-OH position of $\alpha-2,4$ linked Kdo acceptor $\mathbf{5 1}$ with monosaccharide and oligosaccharide donors. Table 1 shows the results of the glycosylation. The use of mannosyl or heptosyl trichloroacetimidates (52 and 53) gave the corresponding $\alpha$-linked trisaccharides (57 and $\mathbf{5 8}$ ) as the sole products (10). The glycosylation using oligosaccharide donors 55 and 56 also proceeded smoothly to afford the corresponding 4,5-branched glycosides in good yield and excellent stereoselectivity (11). This was the first synthesis of a continuously vicinal diol branched structure that contains the core oligosaccharide produced by Neisseria and found in other bacterial LPSs and LOSs.

\section{Conclusions}

Over the past decade, chemical synthesis has been used to obtain a number of interesting inner-core oligosaccharides in high purity. It is expected that additional types of inner-core oligosaccharides will be synthesized in the future, allowing the immunological and biological functions and roles of inner-core oligosaccharides to be elucidated.

\section{Acknowledgments}

The author is grateful to Ms. Maki Taniguchi for technical assistance and would also like to thank his collaborators for their contributions to the project, which was supported by JSPS KAKENHI grants (JP23580474 and JP15K01822). 
Table 1. Synthesis of 4,5-branched and continuously branched inner-core oligosaccharide.

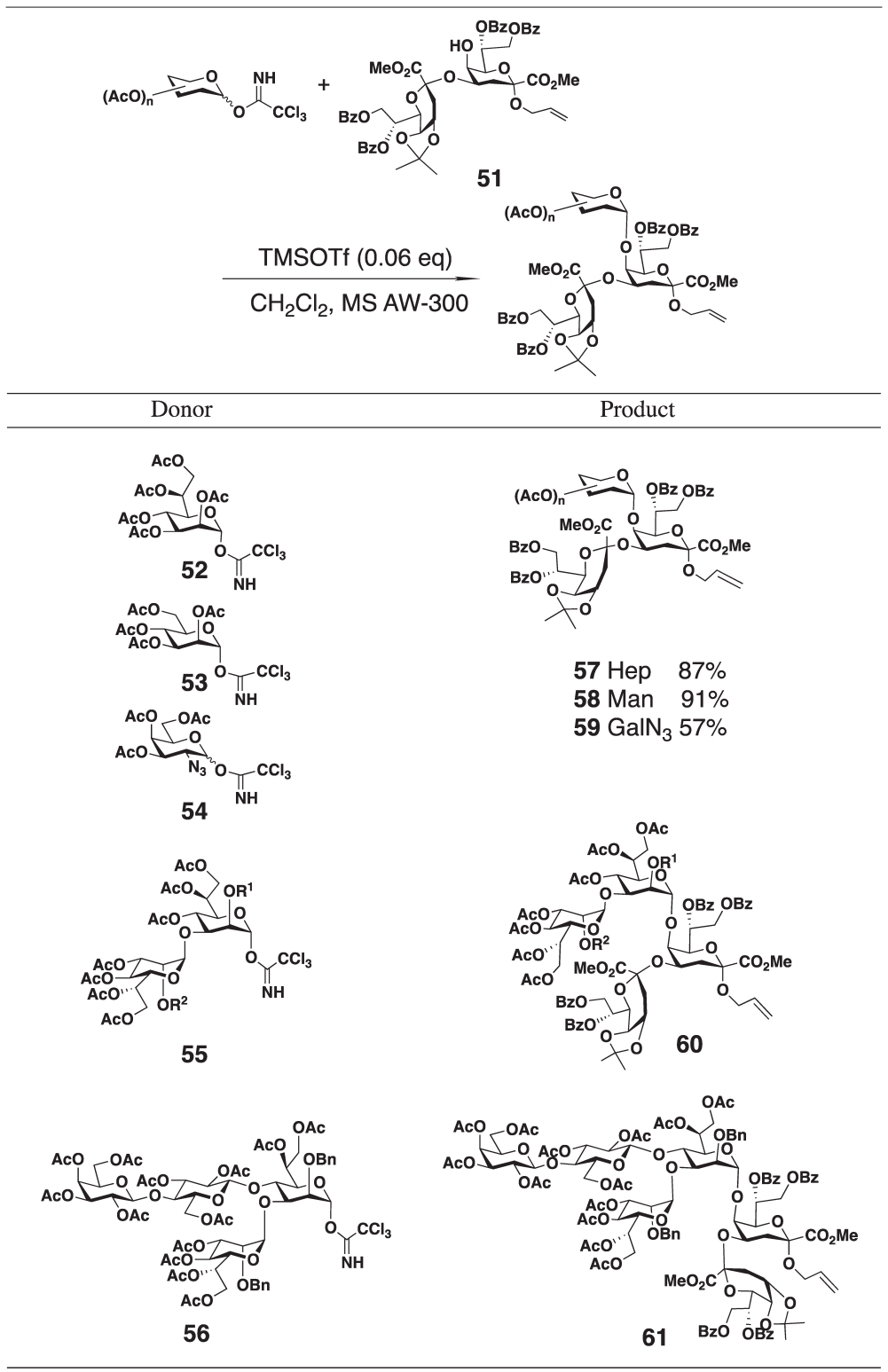

\section{References}

1. a) Zamyatina, A., Holiaus, R., Blaukopf, M., and Kosma, P. (2012) Pure Appl. Chem. 84, 11-21.

b) Blaukopf, M., Muller, B., Hofinger, A., and Kosma, P. (2012) Eur. J. Org. Chem. 2012, 119-131.

2. Pokorny, B., and Kosma, P. (2015) Chemistry 21, 305-313.

3. Pokorny, B., and Kosma, P. (2015) Org. Lett. 17, 110-113.

4. Yang, Y., Martin, C. E., and Seeberger, P. H. (2012) Chem. Sci. (Camb.) 3, 896-899.

5. Yang, Y., Oishi, S., Martin, C. E., and Seeberger, P. H. (2013) J. Am. Chem. Soc. 135, 6262-6271.

6. Reinhardt, A., Yang, Y., Claus, H., Pereira, C. L., Cox, A. D., Vogel, U., Anish, C., and Seeberger, P. H. (2015) Chem. Biol. 22 , 38-49.

7. Huang, J.-S., Huang, W., Meng, X., Wang, X., Gao, P.-C., and Yang, J.-S. (2015) Angew. Chem. Int. Ed. 54, 10894-10898.

8. Boltje, T. J., Zhong, W., Park, J., Wolfert, M. A., Chen, W., and Boons, G. J. (2012) J. Am. Chem. Soc. 134, 14255-14262.

9. Kong, L., Vijayakrishnan, B., Kowarik, M., Park, J., Zakharova, A. N., Neiwert, L., Faridmoayer, A., and Davis, B. G. (2016) Nat. Chem. 8, $242-249$.

10. Yi, R., Ogaki, A., Fukunaga, M., Nakajima, H., and Ichiyanagi, T. (2014) Tetrahedron 70, 3675-3682.

11. Yi, R., Narimoto, H., Nozoe, M., and Ichiyanagi, T. (2015) Biosci. Biotechnol. Biochem. 79, 1931-1945.

12. Pokorny, B., and Kosma, P. (2015) Chemistry 21, 305-313. 


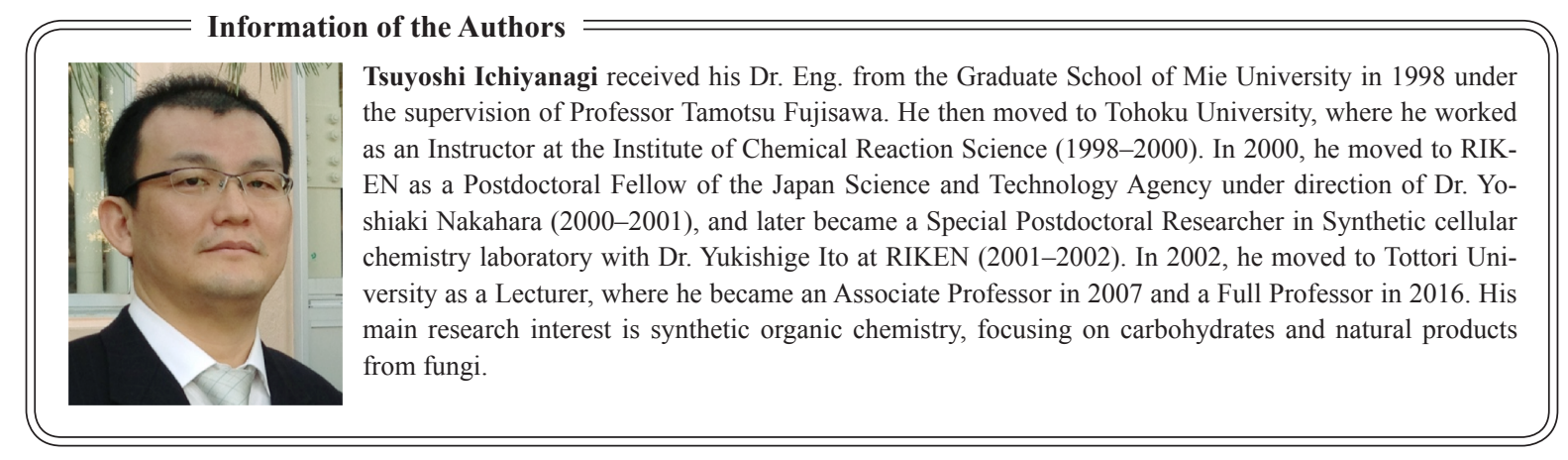

